\title{
Plasma phospholipids and their fatty acid composition in multiple sclerosis
}

\author{
A. MONTFOORT ${ }^{1}$, R. W. R. BAKER, R. H. S. THOMPSON ${ }^{2}$, AND K. J. ZILKHA \\ From the Department of Chemical Pathology, Guy's Hospital Medical School, London, and the National \\ Hospital, Queen Square, London
}

Patients with multiple sclerosis, in whom there is evidence of recent clinical deterioration, have been shown to exhibit a reduction both in the proportion and in the absolute level of linoleic acid in the serum (Baker, Thompson, and Zilkha, 1964, 1966). Since the cholesteryl ester fraction of the plasma lipids contains a much higher proportion of linoleic acid than either the phospholipid or triglyceride fractions, the levels of cholesteryl linoleate in serum from normal subjects and from patients with multiple sclerosis have also been investigated (Baker, Sanders, Thompson, and Zilkha, 1965). It was found that the amount of this fraction of the total serum linoleate is strikingly reduced in patients in the active stages of this disease; the reduction in the level of cholesteryl linoleate in the most seriously affected group of patients amounted to $73 \%$ of the reduction in total linoleate.

Since it is known that transesterification processes between the cholesterol and the $\beta$-linked unsaturated fatty acid of certain of the phospholipids can take place in the serum (Glomset, Parker, Tjaden, and Williams, 1962; Glomset, 1962, 1963), it was decided, in view of these marked changes in the level of cholesteryl linoleate, to investigate also the plasma phospholipids and their fatty acid composition.

\section{SUBJECTS}

The present study was carried out on plasma (oxalate) obtained from 17 'neurological' controls and 27 patients with multiple sclerosis.

The patients with multiple sclerosis, 13 men and 14 women, aged 15 to 58 years, were all attending the National Hospital, Queen Square. As in our earlier work (Baker et al., 1965) they have been divided, on the basis of clinical examination by $\mathbf{K}$. J. Z., into three grades, A, B, and C, showing evidence of slight, moderate and extensive deterioration respectively in the month before taking the blood specimen.

'Present address: Department of Biochemistry, University of Utrecht, Holland.

${ }^{2}$ Present address: Courtauld Institute of Biochemistry, Middlesex Hospital Medical School, London, W.1.
The 'neurological controls', i.e., patients suffering from nervous disorders other than primary demyelinating diseases, were also attending the National Hospital, and comprised seven men and 10 women, aged 18 to 66 years.

The measurements that we have made on the plasma phospholipids have been examined statistically, but since no differences between the two sexes became apparent, the men and women have been treated as one group in each case.

Blood was drawn from each subject from the antecubital vein after an overnight fast, and was immediately transferred into tubes containing oxalate $(2 \mathrm{mg}$. potassium oxalate $/ \mathrm{ml}$. blood).

The subsequent analyses were carried through 'blind', the analyst being unaware of the identity of the specimen.

\section{ANALYTICAL METHODS}

EXTRACTION OF TOTAL LIPIDS Plasma lipids were extracted by the addition of 19 vol. chloroform-methanol (2:1, $\mathrm{v} / \mathrm{v})$ according to the method of Folch, Lees, and Sloane Stanley (1957). The water-washed lower layer was then evaporated to dryness under reduced pressure, and the residue, after repeated evaporation and re-solution in chloroform, was finally dissolved in $50 \mathrm{ml}$. chloroform. Aliquots of this solution were used for the various determinations carried out.

ESTIMATION OF TOTAL PHOSPHOLIPIDS Total phospholipids were determined by estimation of phosphorus in duplicate samples of the total lipid extract by the method of Fiske and Subbarow (1925).

FATTY ACID COMPOSITION OF TOTAL PHOSPHOLIPIDS The phospholipids were first separated from the other lipids present in the total lipid extract by thin-layer chromatography on glass plates $(20 \times 16 \mathrm{~cm}$.) covered by a layer (15 g./plate) of MN-silica gel gS (Macherey, Nagel \& Co.).

Of the washed total lipid extract, $10 \mathrm{ml}$. was evaporated down to $0.5 \mathrm{ml}$. (approx.) which was applied to the plate at 15 spots. To another $10 \mathrm{ml}$. sample, $1 \mathrm{ml}$. of a standard solution containing $\mathbf{0 . 2 2} \mu$ mole of synthetic dipentadecanoyl lecithin (synthesized by Dr. G. H. de Haas) in chloroform was added, and the whole, after evaporation to $0.5 \mathrm{ml}$., was applied to a duplicate plate. 
The plates were developed in $30 \%(\mathrm{v} / \mathrm{v})$ ether in hexane, all operations being carried out in a glove box filled with $\mathrm{N}_{2}$ to prevent oxidation.

After developing, the phospholipids were stained with a solution containing $0.005 \%$ (w/v) Ponceau Red and $0.2 \%(\mathrm{w} / \mathrm{v})$ uranyl nitrate in $0.01 \mathrm{~N} \mathrm{HCl}$ (Hooghwinkel, Hoogeveen, Lexmond, and Bungenberg de Jong, 1959).

The phospholipids were scraped from the plates after staining, and directly subjected to methanolysis by heating in glass-stoppered tubes at $70^{\circ}$ for two hr. under $\mathrm{N}_{2}$ with $18 \mathrm{ml}$. methanol (AR) containing $2.6 \mathrm{~g}$. $\mathrm{HCl} / 100 \mathrm{ml}$. Then $2 \mathrm{ml} .8 \mathrm{~N} \mathrm{NaOH}$ was added, and the heating continued for one hour at $70^{\circ}$.

After cooling and adding $20 \mathrm{ml} . \mathrm{H}_{2} \mathrm{O}, 10 \%(\mathrm{v} / \mathrm{v})$ $\mathrm{H}_{2} \mathrm{SO}_{4}$ was added until the $p \mathrm{H}$ was below 4 , and the free fatty acids were then extracted three times with $25 \mathrm{ml}$. amounts of pentane. The extract was dried over anhydrous $\mathrm{Na}_{2} \mathrm{SO}_{4}$, the pentane evaporated, and after the addition of $1 \mathrm{ml}$. methanol containing $1.5 \%(\mathrm{v} / \mathrm{v}) \mathrm{H}_{2} \mathrm{SO}_{4}$ the mixture was heated for $15 \mathrm{~min}$. at $60^{\circ}$ under $\mathrm{N}_{2}$ to convert the fatty acids to their methyl esters (Baker $\boldsymbol{e t}$ al., 1964). The isolation of the methyl esters and their separation by gas chromatography on 6-ft. polyester columns were as described by Baker et al. (1964). The area of each fatty acid 'peak' on the chromatogram, including that of the methyl pentadecanoate derived from the standard lecithin, was measured by triangulation; the molar correction constants for the different fatty acids were determined as described by Baker et al. (1966).

EXAMINATION OF SEPARATE PHOSPHOLIPID COMPONENTS The proportions of the separate lecithin, lysolecithin, phosphatidyl ethanolamine, and sphingomyelin (together with lysophosphatidyl ethanolamine) components of the total phospholipids were determined by thin-layer chromatography.

Of the total lipid extract, $2 \mathrm{ml}$. evaporated and redissolved in $0.2 \mathrm{ml}$. chloroform, was applied to thinlayer plates $(20 \times 5 \mathrm{~cm}$. $)$ each covered with a layer $(3 \mathrm{~g} . /$ plate) of silica gel G (E. Merck). After developing in chloroform:methanol:water (14:6:1, v/v) according to Müldner, Wherrett, and Cumings (1962), the spots were stained with iodine vapour. They were then scraped off the plates and the amount of silica gel present in each spot was estimated by weighing. The phosphorus present in each spot was determined in duplicate estimations (with suitable blanks for the silica gel and for the other reagents) by the method of Fiske and Subbarow (1925).

\section{RESULTS}

It will be seen from Table I that patients in the inactive phases of the disease or with evidence of only slight clinical deterioration during the preceding month (grade A) showed levels of total phospholipids in the plasma which were indistinguishable from those of the control group. On the other hand, in patients exhibiting evidence of moderate or marked degrees of activity of the disease (grades B and C), the concentration of total phospholipids in the plasma was found to be significantly reduced, and since grades $\mathrm{B}$ and $\mathrm{C}$ do not differ significantly one from another they can be combined to give a single group showing a phospholipid level of $2.63 \mu$ moles/ $\mathrm{ml}$.

\section{TABLE I}

CONCENTRATION OF TOTAL PHOSPHOLIPIDS IN THE PLASMA OF PATIENTS WITH MULTIPLE SCLEROSIS

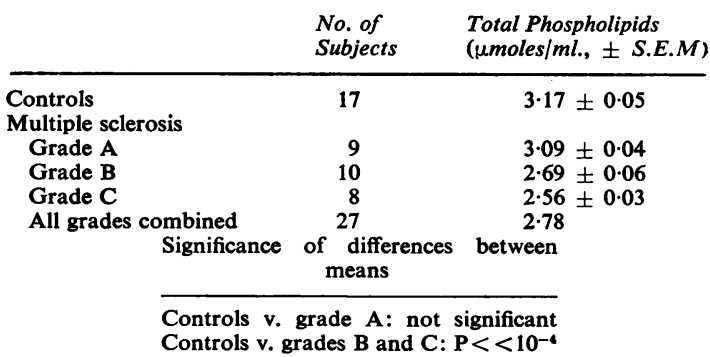

It is therefore not surprising that estimations of the amounts of the different fatty acids contained in these phospholipids also show, when expressed

TABLE II

LEVELS OF PHOSPHOLIPID FATTY ACIDS IN THE PLASMA IN MULTIPLE SCLEROSIS ( $\mu$ MOLES/ML., \pm S.E.M.)

\begin{tabular}{|c|c|c|c|c|}
\hline \multirow[b]{2}{*}{ Fatty Acid } & \multirow[b]{2}{*}{ Controls (17) } & \multicolumn{3}{|c|}{ Multiple Sclerosis } \\
\hline & & Grade $A(9)$ & Grade $B(10)$ & Grade $C(8)$ \\
\hline $1_{4: 0}$ & $0.12 \pm 0.01(9)^{1}$ & 0.09 (3) & $0 \cdot 12(4)$ & $0 \cdot 11(2)$ \\
\hline $16: 0$ & $1.95 \pm 0.05$ & $2.00 \pm 0.06$ & $1.71 \pm 0.04$ & $1.55 \pm 0.06$ \\
\hline $16: 1$ & $0.23 \pm 0.02$ & $0.19 \pm 0.02$ & $0.19 \pm 0.03$ & $0.15 \pm 0.02$ \\
\hline $18: 0$ & $0.66 \pm 0.05$ & $0.62 \pm 0.03$ & $0.50 \pm 0.02$ & $0.54 \pm 0.03$ \\
\hline $18: 1$ & $0.98 \pm 0.05$ & $0.88 \pm 0.05$ & $0.77 \pm 0.05$ & $0.82 \pm 0.04$ \\
\hline $18: 2$ & $1.08 \pm 0.03$ & $1.16 \pm 0.06$ & $1.11 \pm 0.07$ & $0.96 \pm 0.11$ \\
\hline $20: 3$ & $0.26 \pm 0.03$ & $0.30 \pm 0.05$ & $0.20 \pm 0.03$ & $0.24 \pm 0.03$ \\
\hline $20: 4$ & $0.69 \pm 0.05$ & $0.77 \pm 0.08$ & $0.64 \pm 0.06$ & $0.69 \pm 0.05$ \\
\hline Others $^{2}$ & 0.34 & 0.34 & $0 \cdot 18$ & $0 \cdot 28$ \\
\hline $\begin{array}{l}\text { Total fatty acids } \\
\text { (mean of sum of individual }\end{array}$ & & & & \\
\hline fatty acids for each subject) & $6.30 \pm 0.19$ & $6.40 \pm 0.23$ & $5.40 \pm 0.06$ & $5 \cdot 25 \pm 0 \cdot 23$ \\
\hline
\end{tabular}

${ }^{1}$ Nos. in brackets $=$ nos. of subjects.

'Acids have been included in 'others' when present in amounts less than $1 \%$ of the total fatty acids. 
as $\mu \mathrm{moles} / \mathrm{ml}$. serum, the same trend, i.e., no significant difference between the control and grade A groups, but evidence of lower levels in grades $B$ and C (Table II).

This trend becomes more apparent if grades B and $\mathrm{C}$ are combined and compared with the combined control and grade A groups. Myristic acid (14:0) appears to be an exception, but it must be remembered that this acid is present in amounts so small that it has only been listed separately in a very small number of cases.

When the different fatty acid components of the phospholipids are expressed as percentages of the total fatty acids present in these lipids (Table III) it will be seen that there is little evidence of any striking change in the proportions of any of them as we pass from the control subjects to the patients with multiple sclerosis grouped under the three grades of increasing activity. It would seem fair to conclude that although the total amount of phospholipids in the plasma is reduced in patients in the active stages of the disease, the fatty acid composition of the phospholipids shows no evidence of significant change.

The results of estimations of the separate phospho-

\section{TABLE III}

PHOSPHOLIPID FATTY ACIDS, EXPRESSED AS MOLAR PERCENTAGES OF THE TOTAL FATTY ACIDS PRESENT IN THESE LIPIDS

\begin{tabular}{|c|c|c|c|c|}
\hline \multirow{2}{*}{$\begin{array}{l}\text { Fatty } \\
\text { Acid }\end{array}$} & \multirow{2}{*}{$\begin{array}{l}\text { Controls } \\
\text { (17) }\end{array}$} & \multicolumn{3}{|c|}{ Multiple Sclerosis } \\
\hline & & Grade $A(9)$ & Grade $B(10)$ & Grade $C(8)$ \\
\hline $14: 0$ & $1.9(9)$ & $1.4(3)$ & $2 \cdot 2$ (4) & $2 \cdot 1(2)$ \\
\hline $16: 0$ & $30 \cdot 9$ & $31 \cdot 5$ & $31 \cdot 6$ & $29 \cdot 0$ \\
\hline $16: 1$ & $3 \cdot 7$ & 3.0 & $3 \cdot 5$ & $2 \cdot 8$ \\
\hline $18: 0$ & $10 \cdot 5$ & $9 \cdot 8$ & $9 \cdot 2$ & $10 \cdot 1$ \\
\hline $18: 1$ & $15 \cdot 5$ & 13.9 & $14 \cdot 2$ & 15.4 \\
\hline $18: 2$ & $17 \cdot 1$ & $18 \cdot 3$ & $20 \cdot 5$ & $18 \cdot 0$ \\
\hline $20: 3$ & 4.0 & $4 \cdot 7$ & 3.7 & $4 \cdot 5$ \\
\hline $20: 4$ & $11 \cdot 0$ & $12 \cdot 1$ & $11 \cdot 8$ & $12 \cdot 9$ \\
\hline Others & $5 \cdot 4$ & $5 \cdot 3$ & $3 \cdot 3$ & $5 \cdot 2$ \\
\hline
\end{tabular}

lipid components in the plasma are shown in Table IV. The sphingomyelin estimates include the small amount of lysophosphatidyl ethanolamine which is present in plasma, while the trace of phosphatidyl serine is included in the lysolecithin estimates. As is to be expected from the fall in the level of total phospholipids in grades B and C (Table I), the level of lecithin, which is by far the most plentiful of the plasma phospholipids, also shows a reduction in grades B and C. However, when these phospholipid components are expressed as percentages of the total phospholipids (Table IV), it will be seen that no firm conclusion can be drawn about the proportion of each of these phospholipid species owing to the small size of the groups which we have studied.

\section{DISCUSSION}

Earlier work on the levels of phospholipids in the blood of patients with multiple sclerosis has resulted in conflicting statements. Thus, Dobin and Switzer (1954) and Persson (1958) have reported raised levels of phospholipids in multiple sclerosis, whereas Chiavacci and Sperry (1952), Bernsohn and Namajuska (1955), and Šercl, Kovařík, and Jícha (1961) reported lowered levels in this disease. Fog (1951), Wilmot and Swank (1952), Jones, Jones, Howard, and Bunch (1954), and Plum and Fog (1959) reported no significant change.

The results given in this paper show a reduction in the total plasma phospholipids in the patients with multiple sclerosis when treated as a single group. However, as we have already emphasized, in a disease such as multiple sclerosis which shows remissions and relapses it is important to separate the results in those cases with active disease (grades $B$ and C) from those with little or no signs of activity. When this is done it will be seen (Table I) that there is no significant difference between the controls and our grade A patients, but that there is a marked reduction in grades $B$ and $C$ compared with the

TABLE IV

SEPARATE PHOSPHOLIPID COMPONENTS IN THE PLASMA IN MULTIPLE SCLEROSIS

Multiple Sclerosis

\begin{tabular}{|c|c|c|c|c|}
\hline \multirow[b]{2}{*}{ Phospholipid } & \multirow[b]{2}{*}{ Controls (6) } & \\
\hline & & Grade $A(6)$ & Grade $B(6)$ & Grade $C(5)$ \\
\hline \multicolumn{5}{|c|}{ Expressed as umoles phospholipid component/ml. plasma } \\
\hline Leci thin & $2 \cdot 18 \pm 0.06$ & $2 \cdot 10 \pm 0 \cdot 06$ & $1.74 \pm 0.05$ & $1.72 \pm 0.06$ \\
\hline Phosphatidyl ethanolamine & $0.10 \pm 0.01$ & $0 \cdot 10 \pm 0.01$ & $0.07 \pm 0.02$ & $0.10 \pm 0.01$ \\
\hline Sphingomyelin (with L.P.E.) & $0.58 \pm 0.05$ & $0.61 \pm 0.04$ & $0.51 \pm 0.04$ & $0.48 \pm 0.03$ \\
\hline Lysolecithin & $0.34 \pm 0.03$ & $0.34 \pm 0.02$ & $0.38 \pm 0.04$ & $0.28 \pm 0.03$ \\
\hline \multicolumn{5}{|c|}{ Expressed as percentage of total phospholipids } \\
\hline Lecithin & $68 \cdot 2$ & $66 \cdot 7$ & $64 \cdot 4$ & $66 \cdot 7$ \\
\hline Phosphatidyl ethanolamine & $3 \cdot 1$ & $3 \cdot 1$ & $2 \cdot 6$ & 3.8 \\
\hline Sphingomyelin (with L.P.E.) & $18 \cdot 1$ & $19 \cdot 4$ & $18 \cdot 9$ & $18 \cdot 6$ \\
\hline Lysolecithin & $10 \cdot 6$ & $10 \cdot 8$ & $14 \cdot 1$ & $10 \cdot 9$ \\
\hline \multicolumn{5}{|c|}{ L.P.E. = lysophosphatidyl ethanolamine } \\
\hline
\end{tabular}


controls $\left(P \ll 10^{-4}\right)$. The levels of the separate phospholipid components were analysed in a smaller number of cases; no significant change in the proportions was discernible with these small samples.

When we turn to the findings for the levels of the different fatty acids of the total phospholipid fraction we note a decline in the values for all the fatty acids in grades $B$ and $C$, commensurate with the fall in the total phospholipid content in the blood of these patients. There is, however, no alteration in the percentage composition of the different fatty acids. This is in contrast to our finding in the case of cholesteryl esters, where not only did the mean absolute level in $\mu$ moles $/ \mathrm{ml}$. fall progressively with increasing activity of the disease, but the percentage of cholesteryl linoleate in the total cholesteryl ester also fell from a value of $47.5 \%$ in the controls to $40.9 \%$ in grade C (Baker et al., 1965). In the case of the phospholipid linoleate its proportion remains constant even in the most severely affected patients.

It appears therefore that the lowering in the level of cholesteryl linoleate in patients with recent deterioration is not accompanied by any significant change of phospholipid linoleate. The finding that the total phospholipid content is lowered, again only in those cases of most active disease, means that cholesteryl linoleate is not the only blood lipid to show change in this disease.

\section{SUMMARY}

The levels of plasma phospholipids and their fatty acid composition have been determined in specimens from 27 patients with multiple sclerosis and 17 control subjects.

Patients exhibiting the greatest evidence of recent deterioration showed a decline in the level of total phospholipids in the plasma from the 'normal' mean value of $3.17 \mu$ moles $/ \mathrm{ml}$. to a value of 2.56 $\mu$ moles $/ \mathrm{ml}$., whereas patients in remission gave values not significantly different from those of the controls.

The proportions of different fatty acids in the phospholipids were not, however, changed even in patients in the active stages of the disease. Neither did the proportions of different phospholipids show any alteration from the normal.
We would like to thank UNESCO for the award of an IBRO Research Fellowship to one of us (A.M.). Our thanks are also due to Dr. G. H. de Haas, Department of Biochemistry, University of Utrecht, for the gift of a sample of synthetic dipentadecanoyl lecithin, to the physicians in charge of the patients for their helpful cooperation in this work, to the Multiple Sclerosis Society for a grant, and to Mr. K. Kilbourn for his skilled technical help.

\section{REFERENCES}

Baker, R. W. R., Sanders, H., Thompson, R. H. S., and Zilkha K. J. (1965). Serum cholesterol linoleate levels in multiple sclerosis. J. Neurol. Neurosurg. Psychiat., 28, 212-217.

- Thompson, R. H. S., and Zilkha, K. J. (1964). Serum fatty acids in multiple sclerosis. Ibid., 27, 408-414.

,,--- (1966). Changes in the amounts of linoleic acid in the serum of patients with multiple sclerosis. Ibid., 29, 95-98.

Bernsohn, J., and Namajuska, I. (1955). Phospholipid fractions in multiple sclerosis and normal serum. Proc. Soc. exp. Biol. (N.Y.), 88, 124-127.

Chiavacci, L. V., and Sperry, W. M. (1952). Concentration of cholesterol and of lipid phosphorus in blood serum in multiple sclerosis. Arch. Neurol. Psychiat. (Chic.), 68, 37-42.

Dobin, N. B., and Switzer, J. L. (1954). Liver function and other blood chemistry tests in multiple sclerosis. Ibid., 71, 405-424.

Fiske, C. H. and Subbarow, Y. (1925). The colorimetric determination of phosphorus. J. biol. Chem., 66, 375-400.

Fog, T. (1951). On the pathogenesis of multiple sclerosis. Acta psychiat. scand., 26, suppl. 74, pp. 22-31.

Folch, J., Lees, M., and Sloane Stanley, G. H. (1957). A simple method for the isolation and purification of total lipids from animal tissues. J. biol. Chem., 226, 497-509.

Hooghwinkel, G. J. M., Hoogeveen, J. T., Lexmond, M. J., and Bungenberg de Jong, H. G. (1959). Spot tests for phospholipids and their use in paper chromatography. Proc. kon. ned. Akad. Wet., 62, Ser. B (Phys. Sci.), 222-235.

Glomset, J. A. (1962). The mechanism of the plasma cholestero esterification reaction: plasma fatty acid transferase. Biochim biophys. Acta (Amst.), 65, 128-135.

(1963). Further studies of the mechanism of the plasma cholesterol esterification reaction. Ibid., 70, 389-395.

, Parker, F., Tjaden, M., and Williams, R. H. (1962). The esteri-? fication in vitro of free cholesterol in human and rat plasma. Ibid., 58, 398-406.

Jones, H. H., Jones, H. H. Jr., Howard, R. R., and Bunch, L. D. (1954). Metabolic characteristics of multiple sclerosis: chemical abnormalities in the blood and urine of a large series of patients and metabolic balance in two patients. Ann. N.Y. Acad. Sci., $58,656-667$.

Müldner, H. G., Wherrett, J. R., and Cumings, J. N. (1962). Some applications of thin-layer chromatography in the study of cerebral lipids. J. Neurochem., 9, 607-611.

Persson, I. (1958). Concerning the serum lipids in multiple sclerosis. Acta psychiat. scand., 33, 197-207.

Plum, C. M., and Fog, T. (1959). Studies in multiple sclerosis. Ibid., 34, suppl. 128.

Sercl, M., Kovařik, J., and Jicha, J. (1961). Etude des valeurs des lipides du sérum sanguin en cas de sclérose en plaques. Acta neurol. scand., 37, 317-324.

Wilmot, V. A., and Swank, R. L. (1952). The influence of low-fat diet on blood lipid levels in health and in multiple sclerosis. Amer. J. med. Sci., 223, 25-34. 